\title{
Os três pilares de sustentação dos regimes pós-1952 no Egito
}

\section{Isabelle Christine Somma de Castro*}

Universidade Federal de São Paulo, São Paulo-SP

Kandil, Hazem. Soldiers, Spies, and Statesmen: Egypt's Road to Revolt. Londres: Verso, 2012.

A confluência entre história e sociologia, tendência apontada por Peter Burke em História e Teoria Social, tem trazido contribuiçóes relevantes para os especialistas de ambas as disciplinas. Quando uma obra atinge esse objetivo e ainda traz um texto apurado, pincelado com toques de suspense e de humor sagaz, chega a ser quase uma dádiva. Este é o caso de Soldiers, Spies and Statesman: Egypt's Road to Revolt, do sociólogo egípcio Hazem Kandil, atualmente professor associado de St. Catherine's College, Universidade de Cambridge. A obra tem a ambição de cobrir mais de cinco décadas da história política do Egito, buscando esmiuçar os principais pilares que sustentaram, segundo a perspectiva do autor, os regimes autoritários que mantiveram no poder Gamal Abd Al-Nasser, Anwar Al-Sadat e Hosni Mubarak. Esses pilares teriam sido o exército (os soldados), o ministério do Interior (os espiōes) e os próprios dirigentes (os estadistas) - e seu círculo imediato de cúmplices.
Na primeira parte da obra, Kandil concede grande destaque à longa competiçáo entre Nasser e o primeiro e entáo poderoso comandante das Forças Armadas, Abd Al- Hakim Amer - mais tarde marechal de campo, título até entáo desconhecido entre as patentes egípcias. Tal disputa teria engessado o regime e impedido o avanço de reformas estruturais no país. Nasser já havia se consolidado como o principal líder político egípcio após livrar-se de Muhammad Naguib, mas não controlava todas as facçóes existentes entre os militares; Amer era mais hábil. Outro efeito colateral da discórdia foi a crescente paranoia que passou a acompanhar o presidente em relação a ameaças à sua vida e ao seu poder — não sem motivo, considerando a média de duas tentativas de golpe por ano registradas contra o entáo presidente.

Enfatiza-se o sucesso da elaborada rede de apoios entre os militares costurada por Amer em torno de si. Tal estrutura criou uma casta de oficiais endinheirados, que para sustentar seus privilégios mantinha fidelidade a seu líder, desafiando o presidente. Para se esquivar da fortaleza erguida por Amer, Nasser deu início a uma transferência de poder do Exército para órgãos criados e controlados por ele. Essa nova estrutura, de- 
vidamente higienizada de pessoas associadas a Amer, passou a ser controlada por meio de uma intrincada rede de espionagem, que deu origem a novos órgãos de coerção.

Kandil argumenta que a desavença entre os dois homens mais poderosos do Egito criou "dois Estados dentro de um Estado". De um lado estava o ministério do Interior com seus órgãos de espionagem e, do outro, os órgãos de inteligência dos militares. $\mathrm{O}$ aparato político tinha pouca influência nas decisóes, enquanto todo o poder se encontrava concentrado no aparato de segurança - as cadeias egípcias contavam com mais de 20 mil presos políticos no final dos anos 1960.

Nasser sairia vencedor da disputa devido à vergonhosa derrota militar na Guerra dos Seis Dias, em 1967. O vexame foi a desculpa que ele buscava desde a década de 1950 para se livrar de Amer - que não pode ser visto como único culpado pelo fracasso, já que o próprio Nasser realizou uma série de expurgos entre os oficiais antes do conflito. Com a queda do marechal, o Egito iniciou uma nova transição: passou de um Estado militar para um violento Estado policial. Em 2011, essa nova conformação seria um dos principais motivos da revolta que inaugurou o que alguns chamam de Primavera Árabe no Egito. A primeira grande passeata foi convocada para o dia 25 de janeiro daquele ano, o Dia da Polícia, em uma menção aos abusos e à violência policial sofridos pela população.

A estrutura de coerção policial já estava devidamente montada antes de Nasser morrer, em setembro de 1970. Naquele período, o regime era controlado por "centros do po- der", como ficaram conhecidos os três chefes de órgãos de segurança criados por Nasser: Aly Sabri, oficial da inteligência e líder da União Socialista Árabe; Sha'rawi Gomaa, ministro do Interior e chefe da organização secreta Vanguarda (ligada à União Socialista); e Sami Sharaf, chefe do Birô de Informaçóes da Presidência. $\mathrm{O}$ posto de vice-presidente era rotativo, graças à já mencionada preocupação de Nasser com a possibilidade de ser destituído. Sadat ocupava o cargo, exatamente por não ser visto como uma ameaça, quando o popular líder sofreu um ataque cardíaco fulminante, em setembro de 1970. Por ser considerado fraco e manipulável, o vice foi alçado ao posto de presidente pelos chamados "centros do poder", que o consideraram a melhor opção naquele momento. Com alguma perspicácia e bastante sorte — além de ajuda norte-americana Sadat livrou-se do trio, mas a estrutura que lideravam permaneceu.

Sadat manteve a política de diminuir o poder das Forças Armadas, dando maior vigor a este esforço após a guerra de outubro de 1973. Kandil afirma categoricamente que "as políticas de Sadat durante os anos setenta empurraram os militares para o nível de esquecimento e diminuíram sua influência política” (p. 146). Entre as táticas usadas estavam a prisão por traição de generais recalcitrantes, a promoção dos oficias mais incompetentes - e, principalmente, menos aptos a instigarem golpes — , ou a simples eliminação, como o comandante da guarda republicana, Al-Lethy Nassef, que foi empurrado de uma varanda em Londres, e o ministro da Guerra Ahmed Badawy, que 
morreu em um suspeito acidente de helicóptero com mais 13 oficiais de alta patente.

Deve-se observar, contudo, que a explicação para a falta de forte oposição às investidas de Nasser e Sadat contra as Forças Armadas é bastante breve na obra do professor de Cambridge. É verdade que os expurgos realizados entre 1954 e 1974 teriam deixado a corporação militar sem liderança que pudesse ou tivesse o ímpeto de contra-atacar os líderes. Mas parece que falta mais alguma peça na argumentação. A retirada do poder das Forças Armadas pode ter sido utilizada como barganha para a obtenção de apoio popular. A promessa seria trocar estruturas de poder ocupadas por militares por órgãos civis, feita especialmente por Nasser ao criar a União Socialista Árabe, o que daria mais poder ao povo. De qualquer forma, o que acabou ocorrendo foi a substituição de uma hierarquia ligada às Forças Armadas avessa a ambos os líderes por uma estrutura de espionagem aparelhada por eles.

Sadat passou, na segunda metade dos anos 1970, a investir na força do Ministério do Interior. Nomeou membros do corpo policial como governadores das províncias - anteriormente eram designados somente militares. $\mathrm{O}$ presidente também investiu na compra de armas e na contratação de pessoal para as forças de segurança civis. Essas passaram, no ano de 1977 , de 100 mil para 300 mil membros, sendo que muito do investimento foi realizado em detrimento das demandas das Forças Armadas. Não é de se estranhar, como o autor acertadamente aponta, que Sadat tenha sido assassinado por militares, durante uma parada militar
- apesar de toda culpabilidade ser geralmente colocada na conta de "terroristas islâmicos”.

Hosni Mubarak, por sua vez, herdou tal estrutura e não realizou grandes modificaçôes. Colocou os militares definitivamente em segundo plano e fortaleceu ainda mais o aparato de segurança civil, em especial ao alçar oficiais da polícia a posiçóes-chave na política, como o posto de primeiro-ministro e o de secretário-geral do partido governista.

Mas então como um Estado policial desse porte não evitou os protestos de 2011? A resposta dada é que "a arrogância do poder que contagiava o aparato de segurança durante os anos finais do regime fez com que os sinais iminentes de revolta fossem desconsiderados" (p. 235). Para o autor, como o ministro do Interior ignorou informes sobre a real possibilidade de insurgência popular, o Estado estava despreparado para lidar com o evento e mal equipado para combatê-lo. Mais uma vez a explicação se mostra insuficiente, ainda mais ao considerarmos que, como Kandil reconhece, o aparato de segurança se manteve "miraculosamente ileso" depois de tudo o que ocorreu nos últimos anos. É mais provável que a estrutura policial tenha colaborado para a queda do ditador com a finalidade de se manter no poder. Os operadores do Ministério do Interior, sob essa perspectiva, teriam atendido o clamor das ruas, provavelmente pressionando o líder a deixar o cargo, para continuarem intocados e operantes - o que realmente ocorreu imediatamente após a queda de Mubarak e ainda ocorre sob a presidência de Abdul Fatah Al-Sisi. 
Pode-se dizer que na obra sobra palácio e falta sociologia. $\mathrm{O}$ autor se encanta com a centralidade dos atores e deixa de lado outras forças. Os alicerces apontados como essenciais na manutenção da estrutura de poder do regime ajudam a entender, mas não encerram o leque de explicaçóes. Seguindo uma concepção institucionalista, consigna grande ênfase tanto ao Exército quanto aos mecanismos de segurança erguidos pelo regime, criando a ideia de que esses atores foram centrais na articulação das guerras e demais eventos históricos pelos quais o país passou nesse período. A influência da geopolítica, especialmente da ordem bipolar produzida pela Guerra Fria, fica subdimensionada. A ausência de um levantamento do papel desempenhado por movimentos sociais, sindicatos, elites, e até pela imprensa, empobrece a argumentação. Ao mesmo tempo, a quase exclusividade de atores "de cima", em especial da cúpula militar, se contrapóe a uma desvalorização das forças populares, ou seja, "de baixo".

Certamente há outras explicaçóes que dão conta de como o regime se manteve em pé sem sofrer importantes ameaças internas (do regime) e externas (dos que náo faziam parte dele). Uma delas foi a desarticulação da elite e da classe média, grupos que sofreram duro golpe com o êxodo de milhares de estrangeiros e egípcios de origem judaica, grega, italiana, armênia, síria, entre outros, chamados de mutamassirun. Esse vácuo na sociedade provocou desdobramentos de ordem política e econômica, não abordados pelo autor. Passar ao largo desse fator exclui o impacto que essas modificaçóes causaram na construção do regime e de sua resiliência.
Tais problemáticas ficam ainda mais evidentes quando a obra chega ao último capítulo, que trata da revolta popular que derrubou Mubarak em 2011, conhecida pela pouca inspirada denominação "Primavera Árabe”. Fica evidente, e Kandil não esconde isso na Introdução, que o livro estava pronto quando eclodiram os protestos que levaram milhares às ruas do Egito. É provável que uma decisão editorial tenha levado o autor a escrever a toque de caixa um capítulo que abordasse o evento com a obra já concluí$\mathrm{da}$ - pressa que tem se verificado, diga-se, em reediçóes de grandes obras sobre história árabe como The Arabs. A History, de Eugene Rogan, e $A$ History of the Modern Middle East, de Willian L. Cleveland e Martin Bunton. Na obra de Kandil, o capítulo sobre o assunto expóe a fraqueza apontada: onde estavam essas forças populares que se uniram, foram às ruas e desafiaram os órgãos de coerção? Tais órgãos de segurança não foram criados exatamente para conter essas forças? As cadeias lotadas nos anos 1960 e 1970 não indicam que outros atores influenciaram na construção desse estado policial? Houve insurgências? Quais? Certamente os grupos que tomaram as ruas em 2011 não surgiram de uma hora para outra.

O próprio papel da Irmandade Muçulmana, organização islâmica que elegeria o primeiro presidente por voto democrático após a queda de Mubarak, é um exemplo de omissão desconcertante. Kandil somente cita o grupo em eventos pontuais, deixando de lado a influência que a sombra do grupo exerceu pelo menos nas políticas de coerção dos três ditadores. A longevidade da Irman- 
dade apesar da forte repressão, em especial durante o período de Nasser, é um fator importante a ser abordado. Ao mesmo tempo, a organização, apesar de ser vista popularmente como antagonista, desempenhou em vários momentos um papel de contenção política em favor do regime, em especial durante a investida de Sadat contra os movimentos de esquerda na segunda metade da década de 1970.

As questôes apontadas, contudo, não comprometem a obra. Kandil demonstra extremo rigor ao explicar os mecanismos intrincados da política do alto escaláo egípcio durante as mais de cinco décadas abordadas.
Desnuda com maestria os três pilares de sustentação dos regimes autoritários inaugurados pelo golpe dos Oficiais Livres, que são normalmente mobilizados em explicaçôes sobre os meandros da história política egípcia. Foram utilizadas autobiografias recentes de personagens centrais, além de entrevistas, que se mostram bem conduzidas e informadas. Essas fontes, que ainda se encontram quase exclusivamente em árabe, foram certamente bem trabalhadas pelo autor. $\mathrm{O}$ livro apresenta esta contribuição adicional: trazer, ao leitor que não domina o árabe, informaçôes que não se encontram disponíveis em outros idiomas. E isso não é pouco. 